\title{
Algorithm for Computing N Knife Edge Diffraction Loss Using Epstein-Peterson Method
}

\author{
Wali Samuel $^{1}$, Fidelis Osanebi Chucks Nwaduwa ${ }^{2}$, Trust Christopher Oguichen ${ }^{2}$ \\ ${ }^{1}$ Department of Electrical/Electronic and Computer Engineering, University of Uyo, Uyo, Nigeria \\ ${ }^{2}$ Department of Electrical/Computer Engineering, Port Harcourt Polytechnic, Rumuola, Port Harcourt, Nigeria
}

Email address:

samwalliuy@yahoo.com (W. Samuel)

\section{To cite this article:}

Wali Samuel, Fidelis Osanebi Chucks Nwaduwa, Trust Christopher Oguichen. Algorithm for Computing N Knife Edge Diffraction Loss Using Epstein-Peterson Method. American Journal of Software Engineering and Applications. Vol. 6, No. 2, 2017, pp. 40-43. doi: 10.11648/j.ajsea.20170602.15

Received: January 3, 2017; Accepted: January 18, 2017; Published: June 12, 2017

\begin{abstract}
In this paper, algorithm for computing $\mathrm{N}$ knife edge diffraction loss using Epstein-Peterson method and International Telecommunication Union (ITU) knife edge diffraction loss approximation model is presented. Requisite mathematical expressions for the computations are first presented before the algorithm is presented. Then sample $10 \mathrm{knife}$ edge obstructions are used to demonstrate the application of the algorithm for L-band $1 \mathrm{GHz}$ microwave signal. The results showed that for the 10 knife edge obstructions spread over a path length of $36 \mathrm{~km}$ the maximum virtual hop single knife edge diffraction loss is $8.054711 \mathrm{~dB}$ and it occurred in virtual hop $\mathrm{j}=10$ which has the highest diffraction parameter of 0.233333 . However, the virtual hop $\mathrm{j}=10$ has line of site (LOS) clearance height of $2.333333 \mathrm{~m}$ whereas the highest LOS clearance is $3.454545 \mathrm{~m}$ and it occurred in virtual hop $\mathrm{j}=6$. The minimum virtual hop single knife edge diffraction loss is $6.109884 \mathrm{~dB}$ and it occurred in virtual hop $\mathrm{j}=3$ which has the lowest diffraction parameter of 0.008909 as well as the lowest LOS clearance height of $0.142857 \mathrm{~m}$. The algorithm is useful for development of automated multiple knife edge diffraction loss system based on Epstein-Peterson method and ITU knife edge diffraction loss approximation model.
\end{abstract}

Keywords: Diffraction Loss, Diffracting Parameter, ITU-R P 526-13 Model, Knife Edge Obstruction, Epstein-Peterson Diffracting Method, Single Knife Edge Diffraction, Multiple Knife Edge Diffraction

\section{Introduction}

Propagation paths of line of sight microwave signals are in many cases obstructed by obstacles $[1,2]$. When a single isolated obstruction is considered, such as hill or building, such obstruction is approximated as knife edge obstruction [3, 4]. In that case, single knife edge obstruction approach is used to estimate the diffraction loss that signals may suffer as they encounter the knife edge obstruction.

In reality, there are always two or more obtrusions that are often located in the signal path. In such case, multiple knife edge diffraction methods are used to determine the expected diffraction loss $[5,6]$. Studies have shown that computation of multiple knife edge diffraction loss is complex and it complexity increases especially as the number of knife edge obstructions considered increases [7, 8]. As such, available studies limit the computation to two or three obstructions. In this paper, an algorithm that can be used to determine the diffraction loss of any number of knife edge obstruction is presented. The multiple knife edge computation is based on the Epstein-Peterson method [9-13] whereas the International Telecommunication Union Recommendations (ITU-R) P 526-13 knife edge diffraction loss approximation model [14-17] is used to determine the diffraction loss for any diffraction parameter obtained for each of the knife edge obstruction. Sample 10 knife edge obstructions are used to demonstrate the applicability of the algorithm.

\section{Epstein-Peterson Multiple Knife Edge Diffraction Loss Method}

Figure 1 shows $\mathrm{N}$ knife edge obstructions with $\mathrm{n}=1,2,3, \ldots$, $\mathrm{N}-1, \mathrm{~N}$. The transmiter is regarded as $\mathrm{N}=0$ and the receiver is 
designated as $\mathrm{N}+1$. Each of the $\mathrm{N}$ obstructions blocks the line of sight and consitutes an edge that will cause diffraction loss and also introduces a virtual hop in the multiple edge diffraction loss analysis. Each virtual hop has one knife edge that causes diffraction and either one or two other knife edge obstructions that serve as either the virtual transmitter or the virtual receiver for a given virtaul hop. In figure 1 for the $\mathrm{N}$ knife edge obstructions there are $\mathrm{N}$ virtual hops. The first three virtual hops are;

i. Hop1: $\mathrm{H}_{0}-\mathrm{H}_{1}-\mathrm{H}_{2}$ with $\mathrm{H} 1$ as the diffraction edge

ii. Hop2: $\mathrm{H}_{1}-\mathrm{H}_{2}-\mathrm{H}_{3}$ with $\mathrm{H} 2$ as the diffraction edge

iii. Hop3: $\mathrm{H}_{2}-\mathrm{H}_{3}-\mathrm{H}_{4}$ with $\mathrm{H} 3$ as the diffraction edge

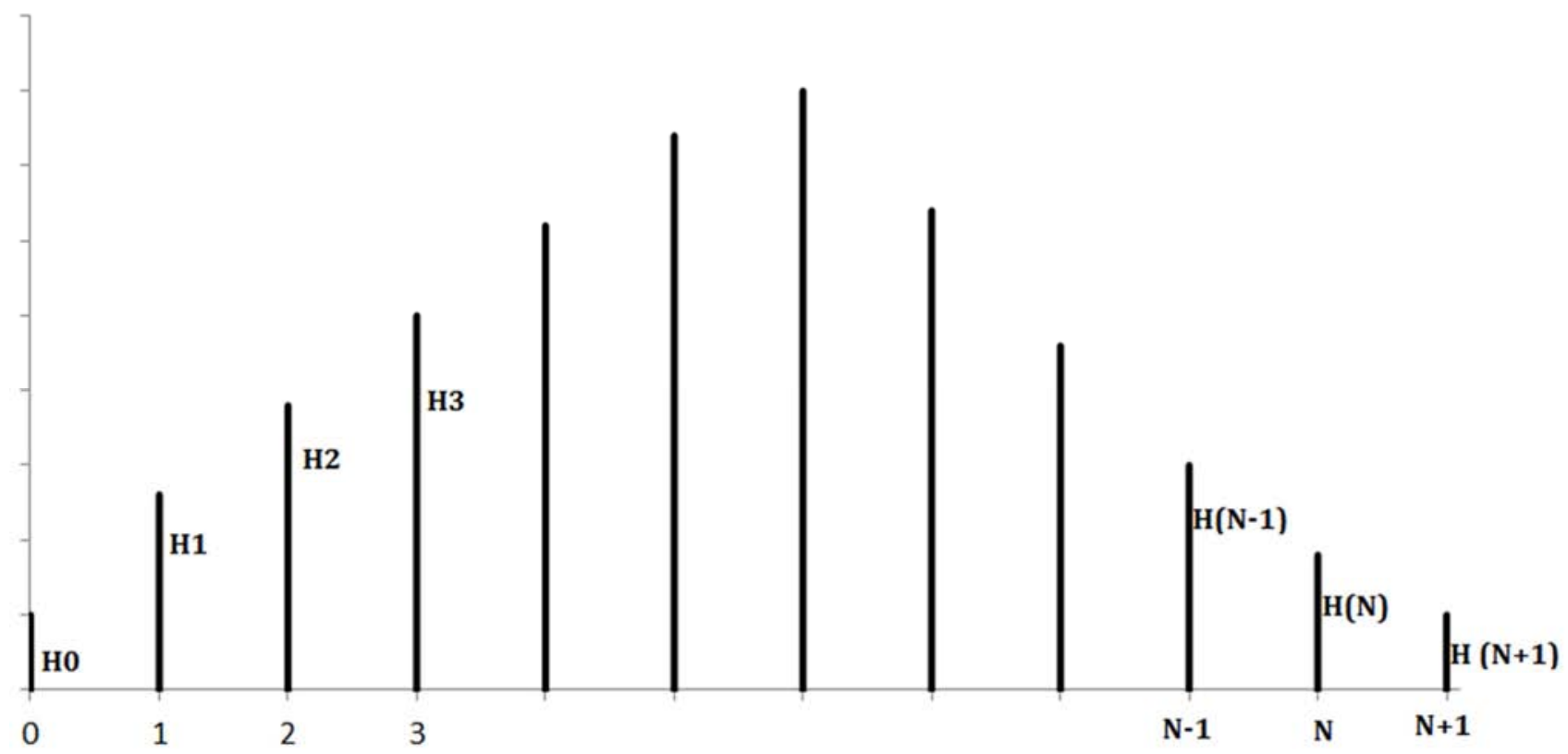

Figure 1. Knife Edge Obstructions.

In figure $1, \mathrm{H}_{j}$ is the height of the obstruction from the sea level. Idealy, $\mathrm{H}_{j}$ takes into account the earth bulge, the elevation and the obstruction height measured from the ground level. Again, $\mathrm{j}=0$ referes to the receiver whereas $\mathrm{j}$ $=\mathrm{N}+1$ referes to the transmitter. $\mathrm{J}=1$ to $\mathrm{J}=\mathrm{N}$ referes to the obstructions 1, 2, 3,... $\mathrm{N}$ respectively. According to Epstein-Peterson multiple knife edge diffraction loss method, for any given hop $\mathrm{j}$, the clearance height to its LOS is given as $\mathrm{h}_{j}$ where [18];

$$
\mathrm{h}_{j}=\mathrm{h}_{\operatorname{Epstein}(j)}=\mathrm{H}_{j}-\mathrm{H}_{j-1}-\left(\frac{\mathrm{d}_{j}\left(\mathrm{H}_{j+1}-\mathrm{H}_{j-1}\right)}{\mathrm{d}_{j}+\mathrm{d}_{j+1}}\right)
$$

The knife-edge diffraction parameter for any hop $\mathrm{j}$ is given as $\mathrm{v}_{\mathrm{j}}$ where [18];

$$
\mathrm{v}_{j}=\mathrm{h}_{\operatorname{Epstein}(j)} \sqrt{\frac{2\left(\mathrm{~d}_{j}+\mathrm{d}_{j+1}\right)}{\lambda\left(\mathrm{d}_{j}\right)\left(\mathrm{d}_{j+1}\right)}}
$$

For any given diffraction parameter, $\mathrm{v}$ the knife-edge diffraction loss, A according to ITU-R 526 is given as;

$$
\mathrm{A}=6.9+20 \log \left(\left(\sqrt{(v-0.1)^{2}+1}\right)+v-0.1\right)
$$

where $\mathrm{A}$ is in $\mathrm{dB}$

Then, in respect of knife-edge diffraction loss for any hop $\mathrm{j}$ with diffraction parameter, $v_{j}$, the knife-edge diffraction loss is denoted as $A_{j}$, where ITU approximation model for $A_{j}$ is given as;

$$
A_{j}=6.9+20 \log \left(\left(\sqrt{\left(v_{j}-0.1\right)^{2}+1}\right)+v_{j}-0.1\right)
$$

where $A_{j}$ is in $d B$

According to the Epstein-Peterson multiple diffraction loss method, the effective diffraction loss for all the $\mathrm{m}$ hops is given as;

$$
\begin{gathered}
\mathrm{A}=\mathrm{A}_{1}+\mathrm{A}_{2}+\cdots+\mathrm{A}_{\mathrm{m}}=\sum_{j=1}^{j=m}\left(\mathrm{~A}_{\mathrm{j}}\right) \\
\mathrm{A}=\sum_{\mathrm{j}=1}^{\mathrm{j}=\mathrm{m}}\left(6.9+20 \log \left(\left(\sqrt{\left(\mathrm{v}_{\mathrm{j}}-0.1\right)^{2}+1}\right)+\mathrm{v}_{\mathrm{j}}-0.1\right)\right)
\end{gathered}
$$

\section{The Procedure For Computing N Knife Edge Diffraction Loss Using Epstein-Peterson Method}

The Procedure for computing $\mathrm{N}$ knife edge diffraction loss using Epstein-Peterson method and the ITU knife edge diffraction loss approximation model is as follows:

Step 1: For $\mathrm{j}=0$ to $\mathrm{N}+1$ obtain height $\mathrm{H}(\mathrm{j})$ of obstruction, where $\mathrm{j}$ includes the transmitter with $\mathrm{j}=0$, the receiver with $\mathrm{j}$ $=\mathrm{N}+1$ and the $\mathrm{N}$ obstructions with $\mathrm{j}=1$ to $\mathrm{N}$.

Step 2: For $\mathrm{j}=1$ To $\mathrm{N}+1$ obtain the distance $\mathrm{d}(\mathrm{j})$ of obstruction (j) from obstruction $(\mathrm{j}-1)$

Step 3: For $\mathrm{j}=1$ to $\mathrm{N}$ compute the LOS clearance heights 
$\mathrm{h}_{j}=\mathrm{h}_{\operatorname{Epstein}(j)} \cdot($ Use Eq 1)

Step 4: For $\mathrm{j}=1$ to $\mathrm{N}$ compute the knife-edge diffraction parameter $\left(\mathrm{v}_{j}\right)$ for each $\mathrm{h}_{j}$. (Use 2)

Step 5: For $\mathrm{j}=1$ to $\mathrm{N}$ compute the knife-edge diffraction loss $\left(A_{j}\right)$ for each $v_{j}$ (Use 4) 5)

Step 8: $A=A_{1}+A_{2}+A_{3}+\cdots+A_{N-1}+A_{N}$ (Use Eq

\section{Numerical Example and Discussion of Results}

The numerical example is for 10 knife edge obstructions located in the path of $1 \mathrm{GHz}$ microwave signal. In this case, $\mathrm{N}$ $=10$. The height, $\mathrm{H}(\mathrm{j})$ of the obstructions for $\mathrm{j}=0$ to $\mathrm{j}=\mathrm{N}+1$ are given in Table 1 while Table 2 shows the distance $d(j)$ of obstruction (j) from obstruction ( $j-1)$ for $j=1$ to $j=N+1$. The results of the computations are presented according to the steps given in the algorithm. In all, for the given 10 obstructions, the total diffraction loss is $67.35065 \mathrm{~dB}$. The path length is the sum of all the $d(j)$ for $j=1$ to $N+1$. From Table 2, the path length is $36 \mathrm{~km}$.

Result for Step 1: The height $\mathrm{H}(\mathrm{j})$ of obstruction for $\mathrm{j}=0$ to $\mathrm{N}+1$, where $\mathrm{j}$ includes the transmitter with $\mathrm{j}=0$, the receiver with $\mathrm{j}=\mathrm{N}+1$ and the $\mathrm{N}$ obstructions with $\mathrm{j}=1$ to $\mathrm{N}$.

Table 1. Height $H$ (j) of obstruction for $j=0$ to $N$, where $j$ includes the transmitter with $j=0$, the receiver with $j=N$ and the $N$ obstructions with $j=1$ to $N$.

\begin{tabular}{lll}
\hline $\mathbf{J}$ & Height $\mathbf{H}(\mathbf{j})$ & Height in $\mathbf{~}$ \\
\hline 0 & H0 & 1 \\
1 & H1 & 4 \\
2 & H2 & 8 \\
3 & H3 & 12 \\
4 & H4 & 17 \\
5 & H5 & 21 \\
6 & H6 & 25 \\
7 & H7 & 22 \\
8 & H8 & 17 \\
9 & H9 & 12 \\
10 & H10 & 7 \\
11 & H11 & 1 \\
\hline
\end{tabular}

Result for Step 2: The distance d (j) of obstruction (j) from obstruction (j-1) for $\mathrm{j}=1$ to $\mathrm{N}+1$.

Table 2. The distance d (j) of obstruction ( $j$ ) from obstruction ( $j-1)$ for $j=1$ to $N+1$.

\begin{tabular}{lll}
\hline $\mathbf{j}$ & $\mathbf{d} \mathbf{( j )}$ & Distance in $\mathbf{~ k m}$ \\
\hline 1 & $\mathrm{~d} 1$ & 1 \\
2 & $\mathrm{~d} 2$ & 2 \\
3 & $\mathrm{~d} 3$ & 3 \\
4 & $\mathrm{~d} 4$ & 4 \\
5 & $\mathrm{~d} 5$ & 5 \\
6 & $\mathrm{~d} 6$ & 6 \\
7 & $\mathrm{~d} 7$ & 5 \\
8 & $\mathrm{~d} 8$ & 4 \\
9 & $\mathrm{~d} 9$ & 3 \\
10 & $\mathrm{~d} 10$ & 2 \\
11 & $\mathrm{~d} 11$ & 1 \\
\hline
\end{tabular}

Result for Step 3: The LOS clearance heights $\mathrm{h}_{j}=\mathrm{h}_{\text {Epstein(j) }}$ for 1 to $\mathrm{N}$
Table 3. LOS clearance heights $h_{j}=h_{E p \operatorname{stein}(j)}$ for 1 to $N$.

\begin{tabular}{lll}
\hline $\mathrm{j}$ & $\mathrm{h}_{i} \mathrm{~L}$ & LOS clearance heights in $\mathrm{m}$ \\
\hline 1 & $\mathrm{~h} 1$ & 0.666667 \\
2 & $\mathrm{~h} 2$ & 0.8 \\
3 & $\mathrm{~h} 3$ & 0.142857 \\
4 & $\mathrm{~h} 4$ & 1 \\
5 & $\mathrm{~h} 5$ & 0.363636 \\
6 & $\mathrm{~h} 6$ & 3.454545 \\
7 & $\mathrm{~h} 7$ & 1.444444 \\
8 & $\mathrm{~h} 8$ & 0.714286 \\
9 & $\mathrm{~h} 9$ & 1 \\
10 & $\mathrm{~h} 10$ & 2.333333 \\
\hline
\end{tabular}

Result for Step 4: For $\mathrm{j}=1$ to $\mathrm{N}$ compute the knife-edge diffraction parameter $\left(\mathrm{v}_{j}\right)$ for each $\mathrm{h}_{j}$

Table 4. The knife-edge diffraction parameter $\left(v_{j}\right)$ for $j=1$ to $\mathrm{N}$.

\begin{tabular}{lll}
\hline $\mathbf{j}$ & $\mathbf{v}_{\mathbf{j}}$ & Diffraction Parameter \\
\hline 1 & $\mathrm{v} 1$ & 0.066667 \\
2 & $\mathrm{v} 2$ & 0.059628 \\
3 & $\mathrm{v} 3$ & 0.008909 \\
4 & $\mathrm{v} 4$ & 0.054772 \\
5 & $\mathrm{v} 5$ & 0.017979 \\
6 & $\mathrm{v} 6$ & 0.170797 \\
7 & $\mathrm{v} 7$ & 0.079115 \\
8 & $\mathrm{v} 8$ & 0.044544 \\
9 & $\mathrm{v} 9$ & 0.074536 \\
10 & $\mathrm{v} 10$ & 0.233333 \\
\hline
\end{tabular}

Result for Step 5: For $\mathrm{j}=1$ to $\mathrm{N}$ compute the knife-edge diffraction loss $\left(\mathrm{A}_{j}\right)$ for each $\mathrm{v}_{j}$

Table 5. The knife-edge diffraction loss $\left(A_{j}\right)$ for $j=1$ to $N$.

\begin{tabular}{lll}
\hline $\mathbf{j}$ & $\mathbf{A}_{\mathbf{j}}$ & The knife-edge diffraction loss in $\mathbf{d B}$ \\
\hline 1 & $\mathrm{~A} 1$ & 6.610527 \\
2 & $\mathrm{~A} 2$ & 6.549428 \\
3 & $\mathrm{~A} 3$ & 6.109884 \\
4 & $\mathrm{~A} 4$ & 6.507288 \\
5 & $\mathrm{~A} 5$ & 6.188371 \\
6 & $\mathrm{~A} 6$ & 7.514422 \\
7 & $\mathrm{~A} 7$ & 6.718608 \\
8 & $\mathrm{~A} 8$ & 6.418562 \\
9 & $\mathrm{~A} 9$ & 6.678846 \\
10 & $\mathrm{~A} 10$ & 8.054711 \\
\hline
\end{tabular}

Result for Step 8: $\mathrm{A}=\mathrm{A}_{1}+\mathrm{A}_{2}+\mathrm{A}_{3}+\cdots+\mathrm{A}_{N-1}+\mathrm{A}_{N}=67.35065 \mathrm{~dB}$

From the results, the maximum virtual hop single knife edge diffraction loss is $8.054711 \mathrm{~dB}$ and it occurred in virtual hop $\mathrm{j}=10$ which has the highest diffraction parameter of 0.233333 . However, the virtual hop $\mathrm{j}=10$ has LOS clearance height of $2.333333 \mathrm{~m}$ whereas the highest is $3.454545 \mathrm{~m}$ that occurred in virtual hop $\mathrm{j}=6$. The minimum virtual hop single knife edge diffraction loss is $6.109884 \mathrm{~dB}$ and it occurred in virtual hop $\mathrm{j}=3$ which has the lowest diffraction parameter of 0.008909 as well as the lowest LOS clearance height of $0.142857 \mathrm{~m}$.

\section{Conclusion}

Algorithm for computing $\mathrm{N}$ knife edge diffraction loss using Epstein-Peterson method and ITU knife edge diffraction loss approximation model is presented. The mathematical expressions required for the computations are first presented 
before the algorithm. Then sample 10 knife edge obstructions are used to demonstrate the application of the algorithm for L-band $1 \mathrm{GHz}$ microwave signal.

\section{References}

[1] Pélet, E. R., Salt, E. J., \& Wells, G. (2004, May). Signal distortion caused by tree foliage in a $2.5 \mathrm{GHz}$ channel. In Electrical and Computer Engineering, 2004. Canadian Conference on (Vol. 3, pp. 1449-1452). IEEE.

[2] Perez-Vega, C., \& Garcia, J. L. G. (1997, September). A simple approach to a statistical path loss model for indoor communications. In Microwave Conference, 1997. 27th European (Vol. 1, pp. 617-623). IEEE.

[3] Östlin, E. (2009). On Radio Wave Propagation Measurements and Modelling for Cellular Mobile Radio Networks.

[4] Baldassaro, P. M. (2001). RF and GIS: Field Strength Prediction for Frequencies between $900 \mathrm{MHz}$ and $28 \mathrm{GHz}$.

[5] Bibb, D. A., Dang, J., Yun, Z., \& Iskander, M. F. (2014, July). Computational accuracy and speed of some knife-edge diffraction models. In 2014 IEEE Antennas and Propagation Society International Symposium (APSURSI) (pp. 705-706). IEEE.

[6] Lazaridis, P. I., Kasampalis, S., Zaharis, Z. D., Cosmas, J. P., Paunovska, L., \& Glover, I. (2015, May). Longley-Rice model precision in case of multiple diffracting obstacles. In URSI Atlantic Conference, Canary Islands.

[7] Lu, G., Wang, R., Cao, Z., \& Jiang, K. (2015). A Decomposition Method for Computing Radiowave Propagation Loss Using Three-Dimensional Parabolic Equation. Progress In Electromagnetics Research M, 44, 183-189.

[8] Durgin, G. D. (2009). The practical behavior of various edge-diffraction formulas. IEEE Antennas and Propagation Magazine, 51 (3), 24-35.

[9] Valtr, P., Pechac, P., \& Grabner, M. (2015). Inclusion of Higher Order Diffracted Fields in the Epstein-Peterson Method. IEEE
Transactions on Antennas and Propagation, 63 (7), 3240-3244.

[10] Conway, M. J., Payne, C. J., Bilén, S. G., \& Koski, E. N. (2015, October). Ground-wave propagation characterization and prediction for HF cognitive radio. In Military Communications Conference, MILCOM 2015-2015 IEEE (pp. 1643-1649). IEEE.

[11] Kasampalis, S., Lazaridis, P. I., Zaharis, Z. D., Bizopoulos, A., Paunovska, L., Zettas, S.,... \& Cosmas, J. (2015, June). Longley-Rice model prediction inaccuracies in the UHF and VHF TV bands in mountainous terrain. In 2015 IEEE International Symposium on Broadband Multimedia Systems and Broadcasting (pp. 1-5). IEEE.

[12] Topcu, S., Goktas, P., Karasan, E., \& Altintas, A. (2015, September). A new approach to diffraction modelling for line-of-sight (LOS) paths. In Antennas and Propagation in Wireless Communications (APWC), 2015 IEEE-APS Topical Conference on (pp. 696-699). IEEE.

[13] Guan, K., Ai, B., Fricke, A., He, D., Zhong, Z., Matolak, D. W., \& Kürner, T. (2016). Excess Propagation Loss of Semi-Closed Obstacles for Inter/Intra-Device Communications in the Millimeter-Wave Range. Journal of Infrared, Millimeter, and Terahertz Waves, 1-15.

[14] Miao, Y. A. N. G., Ji, P. A. N., Yuqi, Z. E. N. G., \& Wei, L. I. (2015). Study on Coexistence between Mobile Satellite System and Radiosonde System in 1668 $1675 \mathrm{MHz}$. Telecommunication Engineering, 55 (3).

[15] Lee, C., Jeon, Y., Shin, I., \& Kim, J. G. (2015). A Study on LEE Model Application for Propagation Loss Estimation of UHF band in Mountain Area. Journal of the Korea Institute of Military Science and Technology, 18 (2), 167-172.

[16] Ichikawa, K., Wang, H., Sato, K., \& Fujii, T. (2015, July). Height power estimation with Radio Environment Database in urban area. In 2015 Seventh International Conference on Ubiquitous and Future Networks (pp. 935-937). IEEE.

[17] ITU-R P.526-13, "Propagation by diffraction," Series of ITU-R Recommendations, Nov, 2013. 